\title{
El papel de las asociaciones de patrimonio cultural en el siglo $\mathrm{XXI}$
}

José Manuel Baena Gallé | Asociación de Profesores para la Difusión y Protección del Patrimonio Histórico Ben Baso de Sevilla

URL de la contribución <www.iaph.es/revistaph/index.php/revistaph/article/view/3816>

En todos los ámbitos de su vida la ciudadanía del siglo XXI se encuentra en múltiples ocasiones en que sólo es un mero convidado de piedra ante la toma de decisiones por parte de las instituciones en aspectos de mayor o menor importancia. En este sentido el patrimonio cultural no es un fenómeno extraño que tenga un funcionamiento muy diferente. Por eso es importante preguntarse cuál es el papel de la ciudadanía en estas cuestiones. Es cierto que actualmente parece existir una mayor conciencia de intervención por parte de los ciudadanos y ciudadanas en los espacios de convivencia aunque en muchas ocasiones no tenga un carácter mayoritario.

Se deberían señalar varias cuestiones en este asunto. En primer lugar la mutua desconfianza existente entre los ciudadanos, los gestores culturales y las instituciones a la hora de cómo afrontar posibles conflictos patrimoniales. En segundo lugar, observar la pequeñez del ciudadano ante estas instituciones que le obliga a asociarse para poder llevar a cabo sus actuaciones, no siendo esto un caso nuevo pudiéndose recordar como ejemplo el papel jugado por la Sociedad de Condueños para la conservación de la Universidad de Alcalá de Henares desde el siglo XIX (GARCÍA GUTIÉRREZ, 2000).

Otro problema es que muchas veces estas asociaciones tienen una finalidad concreta de defensa de algún bien cultural (material o inmaterial) perdiendo la visión global y holística que conlleva el conflicto patrimonial en las sociedades occidentales del siglo XXI. Por ello, uno de los peligros existentes es la utilización de estos movimientos ciudadanos en el juego político concreto y local sin entrar a valorar el fondo de sus pretensiones.

El éxito o fracaso de estos movimientos es difícil de cuantificar. En un principio el simple hecho de consti- tuir el movimiento de actuación patrimonial -reglado o no- ya de por sí es una clara muestra de vitalidad y de afán de participación democrática. Pero a fin de cuentas se van a ver condicionados por varios aspectos entre los que habría que destacar el continuo incumplimiento por parte de las instituciones culturales -públicas o privadas- de lo dispuesto en la normativa patrimonial. Así, hay casos y ejemplos que se pueden observar casi a diario como sería el no cumplir lo dispuesto en la Ley de Patrimonio Histórico Español sobre el acceso a los bienes de interés cultural o las diferentes formas de valorar la intervención en los elementos del patrimonio dependiendo de quién sea el propietario o en relación a los posibles beneficios -en muchas ocasiones económicos o electorales- a corto plazo.

Evidentemente esto lleva a muchos movimientos y asociaciones al agotamiento (tanto vital como económico) al no poderse enfrentar continuamente con estos hechos y ante estructuras muy potentes y de grandes medios. También en este aspecto incide el lógico envejecimiento de los asociados que muchas veces no logran un cambio generacional y eso conlleva el abandono de su participación. Además es patente la falta de interés por parte de las instituciones de una actuación libre y democrática de la ciudadanía ante la situación del patrimonio cultural. La cultura se muestra como un hecho de actuación política y de consumo mediático por lo que se tiende a evitar y obviar toda voz crítica.

¿Es posible la mediación entre los movimientos ciudadanos y las instituciones? Personalmente opino que es complejo ya que hay al menos dos problemas de difícil resolución. El primero de ellos es el pensamiento, por otra parte muy generalizado, de que el criterio correcto a la hora de actuar lo tienen los expertos y por ende las 
instituciones que habitualmente son las que los mantienen. Los ciudadanos sólo deben consumir el producto cultural que se les ofrece sin ningún planteamiento crítico. El segundo es el incumplimiento o el retraso de la correcta aplicación de la normativa existente por parte de las instituciones lo que lleva a batallas legales complejas y donde los mecanismos de control muchas veces no existen o simplemente no actúan. En ese sentido ya ha sido señalado que el futuro de la intervención democrática pasa por la cooperación pública y privada y sobre todo por una ciudadanía activa y comprometida (PASCUAL ESTEVE, 2011).

Para evitar esta situación la participación ciudadana debe afrontar varios retos aunque todos pasan por poner a la ciudadanía en el centro de las decisiones e impulsar la cultura democrática y participativa de nuestra sociedad. El primero de ellos es potenciar y fomentar la cultura del asociacionismo ya que es la única forma y la única posibilidad de que la voz de los ciudadanos preocupados por el patrimonio cultural sea escuchada mínimamente. Seguidamente, afrontar la necesidad de la denuncia pública de aquellos hechos que, en su opinión, atentan contra los elementos que conforman nuestro patrimonio. No es tanto la denuncia legal, costosa e inaccesible para muchos ciudadanos y grupos, sino el facilitar el conocimiento público de estas situaciones para obligar en la medida de lo posible a la intervención institucional para solucionarlas.

Y por último, la difusión y el conocimiento de los elementos de nuestro patrimonio entre la población en general siguiendo la máxima de que lo que se conoce, se valora, se conserva y se transmite. En este aspecto el mundo de la educación -formal o no- tiene un papel primordial. Como afirma el Plan Nacional de Educación y Patrimonio hay que facilitar el conocimiento crítico y reflexivo del patrimonio para así promover "los valores relacionados con la defensa de la diversidad cultural, la biodiversidad y la geodiversidad" para potenciar la empatía sociocultural y socializar el patrimonio.

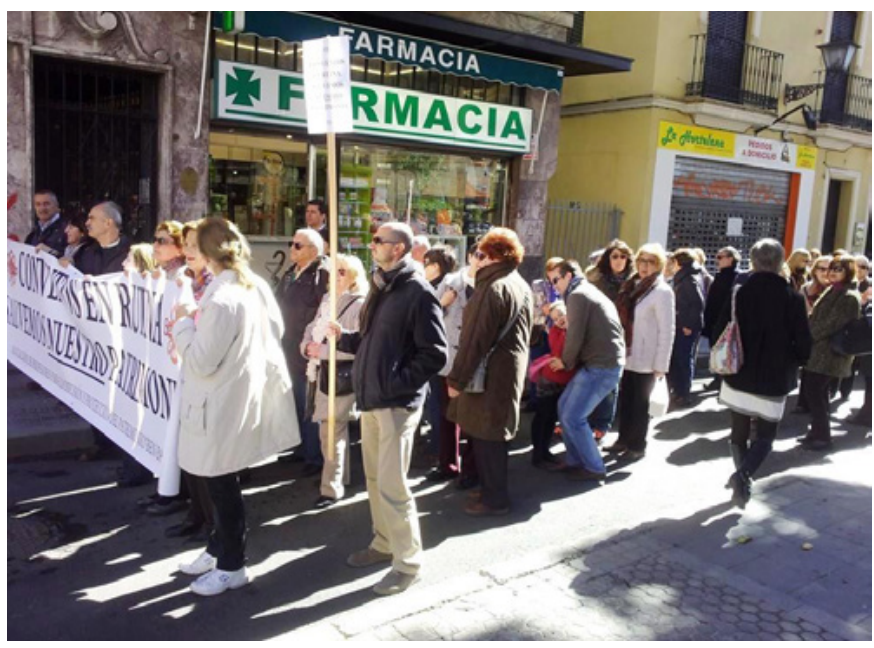

Protesta ciudadana en defensa del Patrimonio. Sevilla, 2014 | foto Asociación Ben Baso

\section{BIBLIOGRAFÍA}

- GaRcía gutiÉRREZ, F. J. (2000) La sociedad de condueños: historia de los complutenses que salvaron una universidad. Alcalá de Henares (Madrid): Asociación de Empresarios del Henares, 2000

- PASCUAL ESTEVE, J. M. (2011) El papel de la ciudadanía en el auge y decadencia de las ciudades. El fin del gerencialismo o la recuperación de lo público y sus actores. Valencia: Tirant lo Blanch, 2011

- LEY 16/1985, de 25 de junio, del Patrimonio Histórico Español. Boletín Oficial del Estado [en línea], n. ${ }^{\circ}$ 155, de 29 de junio de 1985 <https://www.boe.es/buscar/doc. php?id=BOE-A-1985-12534> [Consulta: 25/07/2016]

- PLAN Nacional de Educación y Patrimonio (2013) En Ministerio de Educación, Cultura y Deporte. Instituto del Patrimonio Histórico Español [en línea] <http://ipce.mcu.es/ pdfs/PNEducPatrimonio.pdf> [Consulta: 25/07/2016]

\section{NOTA}

1. Asociación de Profesores para la Difusión y Protección del Patrimonio Histórico Ben Baso: http://www.benbaso. com/; https://issuu.com/benbaso/docs; https://www.face book.com/AsociacionBenBaso. 